\title{
Developing library collections at universities of technology: comparing practices in New Zealand and in South Africa
}

\author{
Carol van Zijl \\ Researcher, University of South Africa \\ carolvz@cyberserv.co.za \\ Elizabeth M Gericke ${ }^{2}$ \\ Department of Information Science, University of South Africa \\ emgerick@mweb.co.za \\ Myrna P Machet ${ }^{3}$ \\ Department of Information Science, University of South Africa \\ machemp@unisa.ac.za
}

Received $15^{\text {th }}$ June 2006
Accepted: $17^{\text {th }}$ August 2006

This paper reports on the findings of a case study carried out for a doctoral thesis conducted through the University of South Africa. The collection development practices and policies at universities of technology in Auckland, New Zealand and in South Africa were compared. Both countries have recently transformed their higher education systems and upgraded polytechnics/technikons into universities of technology. It was found that whilst the Auckland University of Technology Library demonstrates a planned strategy to meet the needs of their researchers through expanding their collection of traditional and electronic media, the South African institution demonstrates little progress. The latter institution has extended mainly its collection of electronic media and has paid little attention to upgrading its collection of print resources. The researcher concludes that unless considerable funding is allocated to South African university of technology libraries, these libraries will be unable to support the information needs of their academics and researchers, and ultimately these institutions will be unable to rise to their anticipated status as universities.

Key Words: Collection development; Universities of Technology; Library materials budgets, New Zealand, South Africa

\section{Background}

In terms of the Technikon Act 125 of 1993, South African technikons began to offer degree courses in addition to the National Diplomas and National Higher Diplomas they had offered in the past. In line with this new focus, research became a critical output of these institutions. In 2004 several technikons were given university of technology status. Loosely, the Australasian model for such institutions was followed.

The new focus on research, and on a higher level of academic qualifications in traditional technikons, has placed a considerable strain on libraries and information services which have historically aimed to meet information needs of underdiplomates. These libraries now have to meet the information needs of researchers at masters, doctoral and even post-doctoral levels, and of the academics preparing and teaching the courses. New curricula have to be developed, research has to be carried out and research projects must be supervised.

In terms of the South African Department of Education's new funding formula for private higher education institutions (SA Ministry of Education 2003), each institution's research output will be audited every year and the following research weightings will apply: I per publication unit, I per research master's graduate and 3 per doctoral graduate (SA. Ministry of Education 2005:4). For the years 2005/6 and 2007/8 these so-called research development grants for which an institution is eligible will be added to each institution's block grant as a matter of course (SA. Ministry of Education 2005:6). This means that a higher subsidy for funding public higher education is given for research than was previously the case.

Because of these factors, it became necessary to investigate the collection development practices, standards and guidelines of technikon libraries in South Africa as these will have to support the information needs of researchers and academics in the new generation of institutions of higher education: the university of technology. In Australia and New Zealand it was found that polytechnics and the new universities of technology did not have the kinds of collections that would be able to support the needs of researchers at university level (Cochrane \& Rickards 1991:147; Powell \& Bushing 199I:12). They have been forced to revise the policies, standards and guidelines which had previously been adequate to

I. Carol van $\mathrm{Zijl}, \mathrm{PhD}$, is a researcher and scholar in the field of Information Science

2. Elizabeth M. Gericke, PhD, Department of Information Science, University of South Africa

3. Myrna Machet, PhD, is Professor and Chair of the Department of Information Science at the University of South Africa 
meet the information needs of academics in a polytechnic. Similarly, collection development foci in South Africa will have to be metamorphosed if technikon libraries are to become the type of research library required in the new dispensation. Funding for library collections has not increased in line with the new expectations, and without a dramatic increase in funding, technikon libraries will be unable to rise above the level of inadequacy at which many have historically operated.

\section{Problem statement}

South African technikons have undergone changes in the past from 'technical colleges' to 'colleges for higher technical education' to 'technikons'. Each change has brought about a higher level of education. The change to universities of technology brings with it a responsibility to produce research in greater volume and at a higher level than before. Were this not to occur, the research and academic programmes at these institutions would lack credibility and accreditation.

Having worked in a technikon library for 15 years, the researcher found that financial constraints have resulted in many technikons reducing financial support to their libraries. In such technikon libraries, increases in materials budgets have not kept up with inflation. This means that instead of expanding collections, institutions have been able at best to maintain collection sizes, and in some instances the weeding and shrinkage of collections has meant that collections have shrunk in size. This has resulted in collections that are inferior to those of universities in terms of number and variety of books, journal subscriptions, audiovisual material, CD-ROM and online bibliographic and full-text databases (Van Zijl 2002).

The key problems to be addressed in this study are: to what extent do the collection development and management policies, guidelines and standards adhered to by universities of technology satisfy the information and research needs of researchers in these institutions, and how do the collection development policies, standards and guidelines used in universities of technology in South Africa and New Zealand compare?

\section{Research method}

A case study of collection development policies, standards and guidelines at a university of technology in New Zealand was undertaken, to determine what that library had done to change from a college to a university library. This was compared with a similar case study at a South African university of technology.

This was essentially an exploratory, descriptive and comparative qualitative investigation. The empirical part of this study consists of case studies of an established Australasian university of technology: Auckland University of Technology (AUT) and of a newly accredited South African university of technology: X University of Technology (XUT) ${ }^{4}$.

In the literature, study documents which provide a frame of reference for collection development policies, standards and guidelines, were studied and their contents synthesised.

The nature of the study dictated the use of the case study method. The comparisons need to be dealt with qualitatively. Kratwohl (1993:31I) states that the data in qualitative research, which are often reported in the form of a case study, are '... accounts of careful observations, including detailed descriptions of context and nearly verbatim records of conversation. They may also include analyses of documents and records'. Another reason for selecting the case study method is that case studies provide detailed analysis of a limited number or conditions or events (cases) and their relationships (Soy 1997: I), which was necessary in this study.

The researcher contacted the University Librarians of AUT's and XUT's libraries to obtain permission to study collection management procedures and policies at those institutions. Throughout the study, staff members at these institutions were contacted via email or telephone to carry out the case studies. Policies, guidelines and other documents were sought and their websites were also examined critically, to ensure external validity of the data.

The researcher took on the role of an impartial observer of the policies and practices followed at the universities of technology. An attempt was made to build up a rapport and to become a trusted confidante to both informants. Ethical practices were adhered to in the reporting of the studies undertaken. As the researcher works at neither of the universities of technology subjected to scrutiny in this case study, it was possible to be objective in the study. Although every effort was made to give an unbiased interpretation of the data, first-hand knowledge of the way in which a South African technikon collected and managed collections at the turn of this century colours the researcher's worldview. Similarly, her lack of first hand exposure to New Zealand universities of technology means that the researcher relies solely on documentation, written and verbal data to formulate an understanding of the practices at Auckland University of Technology. These might be biased in favour of the institution, but the researcher must accept that the informant and the documentation reflect the position there accurately. In an attempt to ensure that the data presented in the case study is valid, the researcher correlated the information given by informants with documented information and data in printed information sources and on the websites of the institutions studied. The factual data is reflected consistently in this

4. The South African university of technology wishes to remain anonymous 
triangulation process, which leads the researcher to conclude that the facts are correct and that opinions given by the informant are honest.

A narrative style is used for reporting the findings.

\section{Findings}

It was found that the two institutions had similar histories, except that AUT became a university of technology (in 2000) five years earlier than XUT (in 2005). Currently there are approximately 15,000 full-time equivalent (FTE) students registered at AUT, and approximately 9,000 at XUT. In addition, there is more of an emphasis on the engineering sciences at XUT than at AUT. Apart from this, the faculties and courses offered are similar at the two institutions. There is the same emphasis on research at the two institutions. The student numbers are higher at AUT than at XUT, but the student numbers at both institutions mean that they fall into the category of medium-sized colleges or universities (Faculty use of an academic library reference collection 1998:57). Overall, the two institutions do not differ substantially and a comparison would be fair.

\subsection{Collection development goals}

The goals, visions and objectives of AUT's library show a focused progression towards becoming the kind of library academics would expect to find at a university of technology. The chronological development of their goals relating to collection development reveal their priorities and ideals during these years of transition from a polytechnic to a university of technology. As far back as 1996, the Institute Librarian stated that the general way in which the Institute operated influenced the library, especially as the emphasis of academic activities was to become more research orientated. She believed that it was the introduction of postgraduate degrees in particular that would have a considerable impact on the library (Blanchard 1996:I). The extent to which policies, standards and guidelines of collection development support the information needs of academics must be reflected in the stated and inferred goals of the libraries concerned.

In 1998, the library's goals included the following (Saw 1998:32-33):

- Developing a comprehensive coverage for basic texts and serials used in teaching.

- Building a collection to support new programmes.

- Building a collection to support research and development at Auckland Institute of Technology (AIT).

- Provide subscriptions to access full-text electronic database coverage at the rate of at least one each per faculty. These objectives for 1998 include plans to build up a core collection of library resources to support the teaching function at AIT at an undergraduate level as well as to build up a collection that will meet the information needs of researchers and postgraduate students. Although full-text databases were not used very extensively in polytechnic libraries at that time, the goal to subscribe to at least one full-text electronic database per faculty was forward-looking and demonstrates a willingness to embrace new technology to move closer to the university library they were to become in 2000.

In anticipation of becoming a university of technology, goals and objectives were set in 1999 that gave clear guidelines regarding collection development at AIT. Objectives for that year include:

- To provide excellent customer service by providing ease of access to electronic information resources, providing electronic and physical collections that support teaching and research needs as well as providing access to remotely held items (Saw 1999:I).

- To provide core services including information in print, electronic resources and audiovisual materials, document retrieval services and access to electronic information (Saw 1999:30).

- To have a book stock of 200,000 volumes and 65,000 volumes of serials by 2008 (Saw 1999: I I).

In this year, library management at AIT paved the way for the library's transformation from a polytechnic library to a university library. The objective to build up their book and serial stock to a specified number of volumes over a specified timeframe made it possible to make applications for additional funding from the institution. The objective of 200,000 books and 65,000 volumes of serials was taken with due consideration for the financial position of the parent institution as well as international and national standards for print collections in medium-sized university libraries. The goal is conservative compared to international standards. After becoming a university of technology, the goals and objectives became broader, reflecting the change from a polytechnic library to a university library.

XUT has less clearly defined goals and objectives, especially those giving direction for collection development and management to meet the information needs of researchers, postgraduate students and academics. In 1999, the mission of their library was to provide 'a dynamic information service to enhance the academic process and the mission of $X$ Technikon.' The only objective relating to collection development was: 'Balanced, relevant collection development' (Van Zijl 1999:I). It is notable that the technikon had already begun conferring degrees up to a doctoral level at that time, yet no mention is made of a project to upgrade the quality and quantity of the library's collection.

In $200 \mathrm{I}$ a consultant was contracted to lead the process of formulating a three-year strategic plan for the institution to position it correctly for possibly becoming a university of technology. In the lengthy report covering this strategic plan, the 
library was not mentioned once as a part of the institution that would need to be upgraded to meet the future needs of the academics and students (XUT 200I). At the time the book stock stood at around 46,000 volumes and there were fewer than 500 current journal subscriptions.

In 2003, a year before the institution became a university of technology, the vision of the X Technikon Library was: 'to provide dynamic information access to achieve total customer satisfaction'. The mission statement still bore no reference to quantifiable means of upgrading the library's collection. Again there was a reference to 'relevant and balanced stock of information resources', but no quantifiable objective to use as a guideline.

Due to shortfalls in the monographic and serial collections in the library, this researcher believes that the goals formulated by the library should reflect clear strategies to upgrade the collection to be more in line with accepted norms for university libraries.

4.2 Information resources budgets

AIT was given permission in 1989 to offer degrees and master's courses. This period thus reflects a time that the library was developing from that of a college that prepared students for diplomas, to one that offered graduate and postgraduate courses. The first graduation ceremony was held in 1993. The library funds remained under the control of the library but were allocated to subject areas according to the number of FTE students enrolled. A proportion of the funds were set aside for interdisciplinary purchases. Staff reference funds were supplied by the departments to buy material for staff to use on long-term loan from the library (Blanchard 1994:22).

In order to build up the library's collection into one that supported the new status of AIT, in 1996 a basic assumption was adopted by the institution that the library would be funded at a minimum of NZ $\$ 340$ per FTE student ${ }^{5}$. This amount excluded allowances made for depreciation. One of the library's objectives was to ensure that funds were available to provide library materials in a quantity or of a quality that matched international expectations of a comparative institution (Blanchard 1996:40). In 1990, a study had been undertaken comparing the funding of comparable institutions. This revealed that the allocation of funds to the library would have to be doubled if AIT wanted to match the allocations of libraries in comparable degree-granting New Zealand institutions. A similar comparison in 1994 revealed similar results. In that year the expenditure on the library per FTE student at AIT was NZ\$236 (Blanchard 1996:4I). Although the allocation per FTE student was not doubled, it had been increased by $44 \%$. This shows that the library and AIT itself realised that offering degrees and master's courses in addition to the diplomas previously offered, meant that the library had to be upgraded.

In 1997 the capital budget increased by $17 \%$ to $\$ 700,000$. In addition $\$ 300,000$ was given for the purchase of a new computer system (Saw 1997:3). Although expenditure looks fairly consistent from 1996 to 1997, there was an increase of approximately $17 \%$ for all the types of information resources. In 1998, there was a further increase of $56,5 \%$ in the library's materials budget. Out of this, $5 \%$ was set aside for the purchase of equipment with which to access electronic resources (Saw 1998:13). An Information Resources formula was developed in 1998 for the allocation of the budget to the faculties based on FTEs, with postgraduate and research weightings (Saw 1998:13). In 1999, the library was awarded a ten percent increase in capital budget (Saw 1999:2). More than half of the total budget was spent on monographs (Saw 1999:10).

In 2000 AIT became the Auckland University of Technology. Plans to improve the quantity of information resources were on track as budgets had shown substantial and sustained growth since the institution began offering degree and master's courses. Changes have been reflected in the move to electronic resources and the growth of $334 \%$ in materials budgets over the period 1996 to 2000 , both of which have been associated with providing these new services, remote access and availability of electronic databases. Budget growth has kept up with student registration levels at AUT.

The trend to increase the proportionate amount spent on electronic resources and to decrease that spent on print serials began in 2000 . Then in 200 I, the library's acquisitions budget was increased by $50 \%$. This demonstrated AUT's commitment to increase and improve library resources as outlined in its 5-year plan in I998 (Saw 200 I: 10). From 200I, the library committed itself to increase electronic access to information and to avoid duplication between print and electronic versions of serials. It should be noted that the proportion of the total budget spent on books and non-book material including video cassettes did not diminish substantially. This demonstrates a resolve to build up the library's collection of books and audiovisual material, in addition to increasing access to electronic material.

5. At an exchange rate of approximately R4.40 per NZ\$ in 2005 , this amounts to nearly RI,500 per FTE student. 


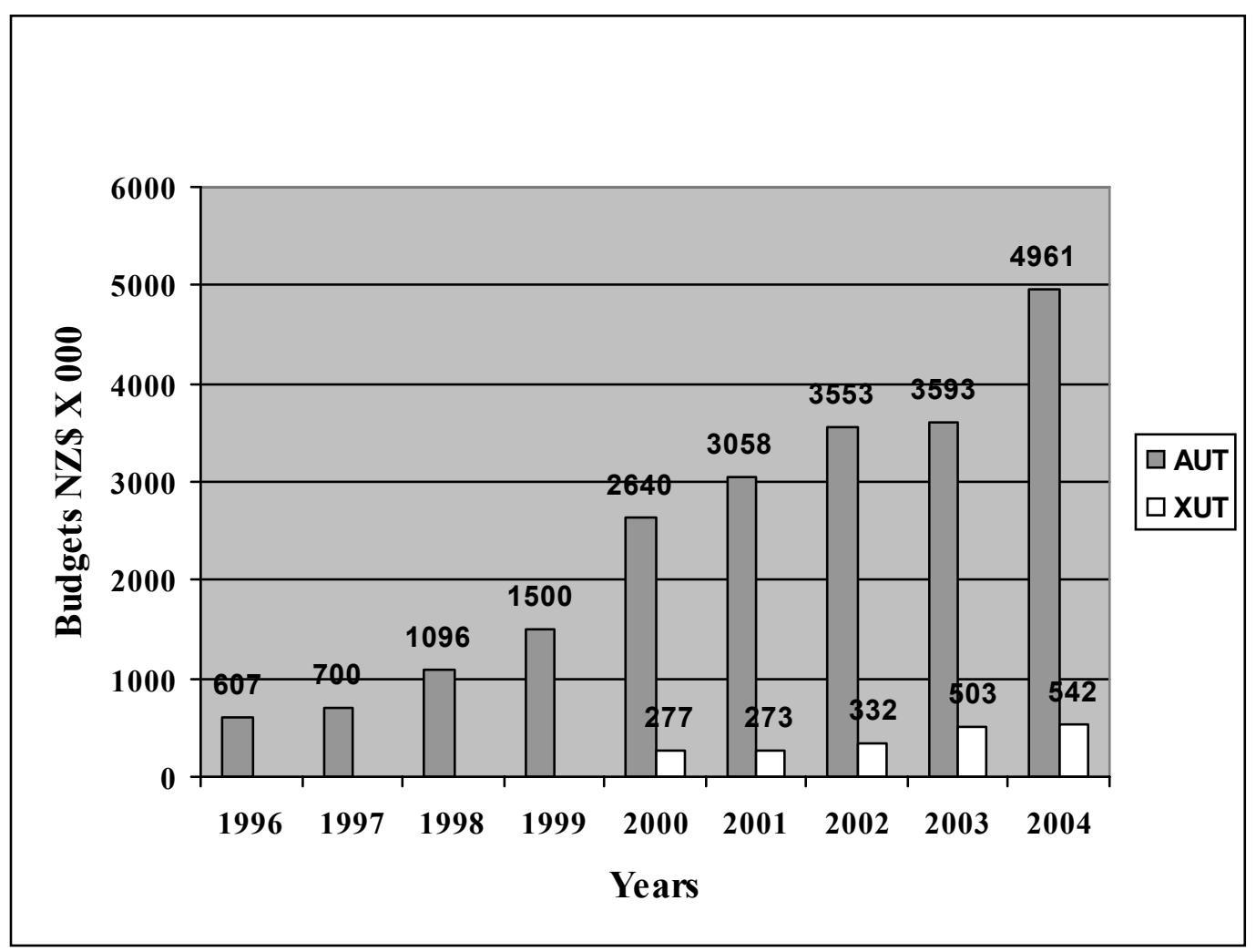

Figure I Materials budgets

A look at increases in

materials budgets from 1996 to 2004 gives another picture of AUT's commitment to improve the size and quality of their library collection to meet changing needs. This can be seen in figure I. Over this period, the materials budgets at AUT (including print, non-book and electronic information resources) have increased by $717 \%$.

Statistics are not available of the total library expenditure per FTE student until 2000. Table I, however, shows what was allocated to the library from 2000 to 2003 per FTE student (Dewe 2003:10). The allocations have surpassed the target of NZ\$340 per FTE student by a large margin.

Table I Total library expenditure per FTE student at AUT

\begin{tabular}{ccccc}
\hline Year & 2000 & 2001 & 2002 & 2003 \\
\hline \$ per FTE & 486 & 568 & 566 & 526 \\
\hline
\end{tabular}

The gradual decline since 200I, is coincidental as the allocation for library materials is not worked out according to the number of FTE students at the institution. Since AIT was given permission to offer degrees and master's courses, they have demonstrated a clear resolve to provide additional funding to upgrade the library's collection from that of a college to that of a medium-sized university. Materials budgets have risen by large amounts each year since 1996 with a view to improving the quality and quantity of the resources available in or through the library. As technology has advanced AUT has had to make additional funds available to provide access to online databases. In addition, adequate funding was provided to allow the library's physical collection to develop in line with the higher level of information needs of researchers, academics and postgraduate students at a university of technology.

The total library budget at X Technikon and later XUT came from only the institution itself. Although some amounts are donated by trade and industry for specific purposes, these cannot be included in collection development programmes as they are not ongoing and cannot be relied upon as sources of income. One amount is allocated for the purchase of books and audiovisual (non-book) material. Another amount is allocated for serial subscriptions and yet another for electronic resources. Out of the monographs allocation, funds are allocated to the various faculties according to the number of FTE students, average book price, circulation statistics and certain other factors. 


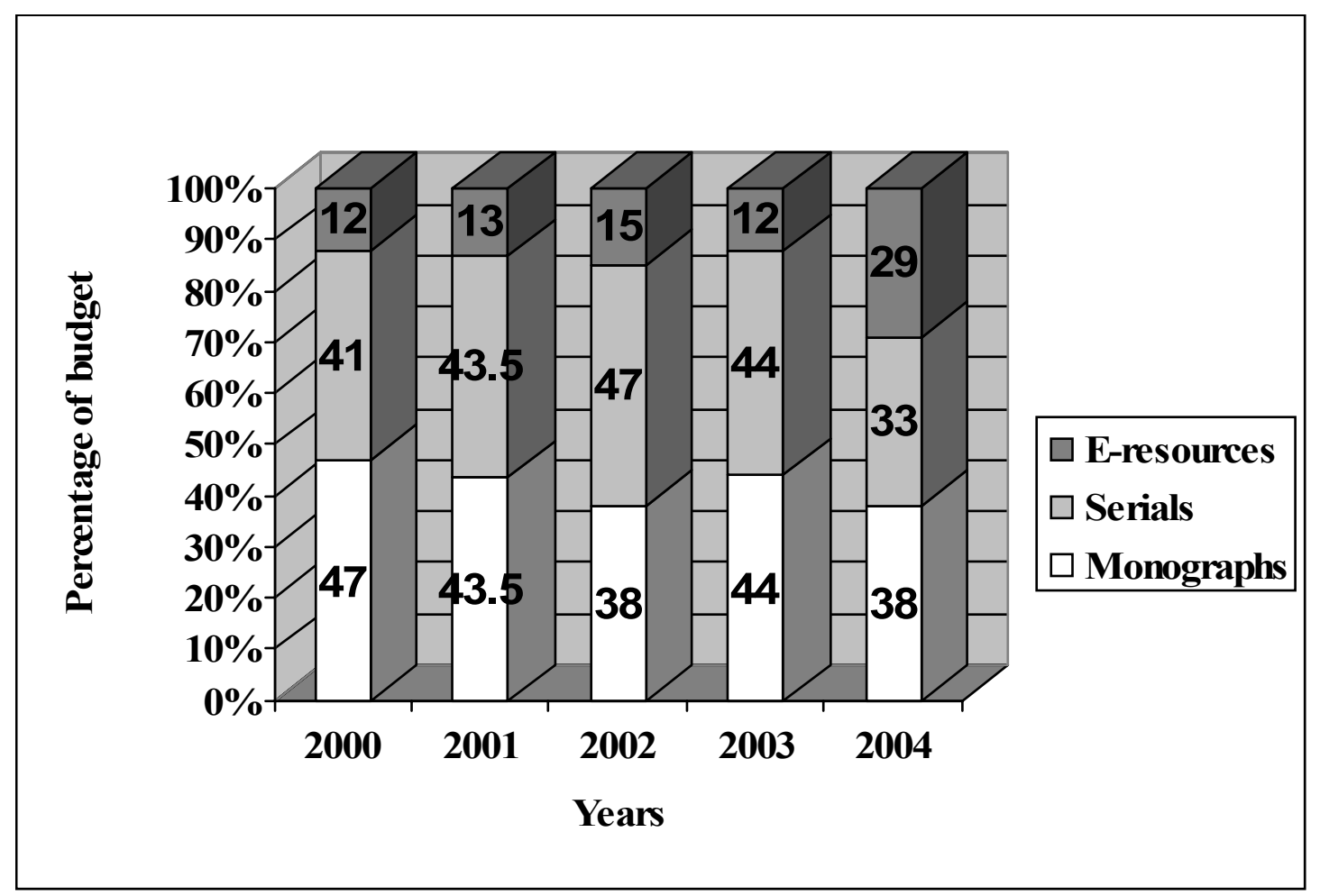

Figure 2 Proportion of budget spent on various formats - XUT

Figure 2 shows the proportionate amounts allocated for the various formats in XUT Library. One amount is allocated for the procurement of books and audiovisual material. This amount is reflected under the heading "Monographs" in figure 2. It can be seen that a larger proportion of the materials budget was allocated to electronic resources in 2004 than in previous years. This was the year in which $X$ Technikon became $X$ University of Technology. No information was given regarding the size of the materials budgets at XUT, but this chart shows that an attempt was made in 2004 to extend the library's collection through providing access to a larger number of aggregated services whereby users could access fulltext electronic journals. Increased funding for these databases is a positive measure on the library's part to make up for the inadequate collection of print resources at the institution.

X Technikon conferred its first degree in 1995, two years after AIT did so. There was no possibility of building a library collection better able to meet the information needs of researchers and postgraduate students, because throughout the 1990s the library was limited in its budget increases to approximately $5 \%$ per annum, as were the rest of the departments at the Technikon. Although various motivations were submitted to the managing body of the institution applying for additional funding because of the new demands made on the library due to the institution's ability to offer degrees up to a doctoral level, no additional funding was given (Q 2005a:I).

In the five-year period from 1996 to 2000 , the library's materials budget had risen by only $20 \%$. In view of the fact that the average price of print resources had more than doubled in this period, the increases in the budget made any meaningful collection growth impossible. In fact, due to the small size of the print collection relative to the number of students and other library users at the technikon, the books and journals were overused and many had to be deselected due to their poor condition. As seen in Figure I, the materials budgets at XUT are considerably smaller than those of AUT. There was a $53 \%$ increase in the allocation in 2003, the year before becoming a university of technology, which demonstrates a desire to provide access to more information resources. However, compared to the measures taken by AUT to upgrade the library's collection to that of a university when they were allowed to confer degrees, XUT's lack of financial backing to build up the collection beyond that of a college or undergraduate institution is a cause for concern.

\subsection{Collection size and composition}

Although there is no definitive standard for medium-sized academic libraries, research shows that academics expect their libraries to meet most of their information needs immediately from local stock. Findings indicate that there is a direct relationship between the prestige of an academic institution and the size of its library collection (Liu 200I).

In 1994, the Institute Librarian at AIT realised that changes would have to be made because of AIT receiving permission to grant degree and master's courses in future (Blanchard 1994:7). In 1990 and 1994 the library's collection was evaluated and found wanting with regard to its ability to meet the needs of researchers and postgraduate students. It 
was indicated that a medium-sized academic library at that time would be expected to hold about 250,000 volumes of monographic material (Blanchard 1996:4I). At that time, AIT's library held approximately 55,000 volumes. Furthermore the New Zealand Qualifications Authority (NZQA) stated in their report that the funding of the Library was inadequate to provide proper resources for the support of higher degrees (Blanchard 1996:38). The Librarian maintained that printed resources were the main estimator used to evaluate the adequacy of the library's stock.

In 1996, which shall be regarded as the base from which collection changes started to increase, the library's collection was as reflected in table 2 (Blanchard 1996:28-29).

Table 2 AUT collection strength - 1996

\begin{tabular}{|c|c|c|c|}
\hline Monographs & Non-book & Serials & Bibliographic resources \\
\hline \multirow{4}{*}{55,036} & 6,454 & I,785 titles & Print indexes -20 \\
\hline & & & Microfiche index - I \\
\hline & & & CD-ROM index - 23 \\
\hline & & & Diskettes - 12 \\
\hline
\end{tabular}

The library management of the Auckland Institute of Technology recognised that they would have to embark on a process of building up their collection in line with international and national standards, more sophisticated and advanced user needs and the capability of the institution to provide the funding for such evolution. Progress in the collection of different formats will be dealt with separately.

Due to budgetary restrictions at X Technikon and XUT, the paradigm shift from technikon to university of technology is not as clearly visible in the collection development practices at XUT. The exact number of serial subscriptions and monographic volumes in the library's stock before the institution was allowed to confer degrees is not available, but the stock of books stood at approximately 43,000 volumes at that time and there were around 500 current journal subscriptions. The rate of growth in all the formats included in the collection will be shown to be far below that of AUT Library.

\subsection{Books}

AUT was aware that the library's collection of monographs was substandard and embarked on a project to try to bring the collection in line with that of similar medium-sized universities. In Figure 3, the growth in the collection of books in the AUT Library is depicted. This figure shows that the stock of books at AUT has increased by I33\% in 9 years. Since becoming a university of technology in 2000, the stock has increased by $53 \%$ (Jenks 2005:3). The projected goal of 200,000 volumes of monographs has not yet been reached, but it can be seen that the collection is now much more comprehensive than it was before the institution began offering degree courses. Although shown in Figure 3, the growth in XUT's collection of books will be discussed later.

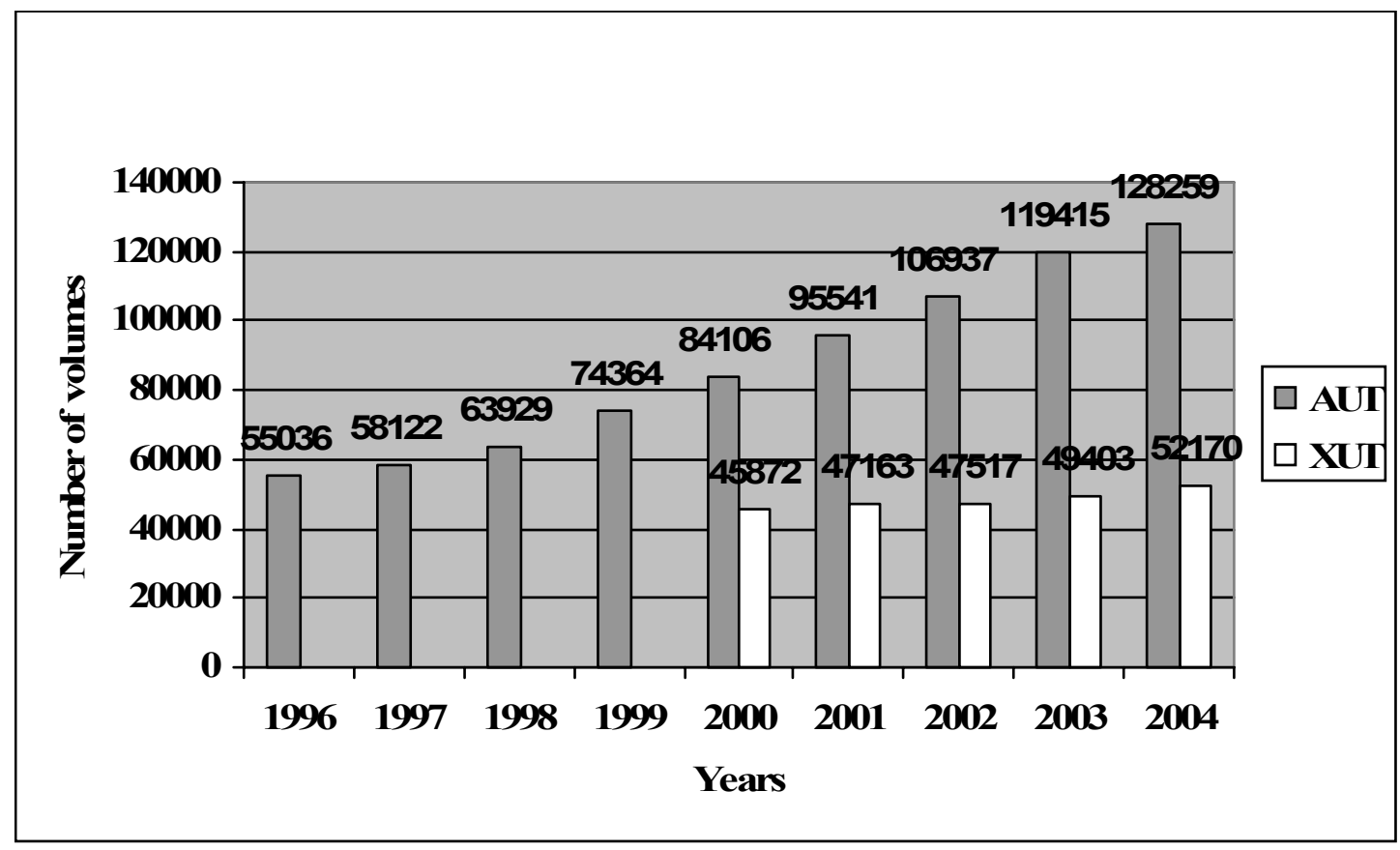

Figure 3 Size of book stock 
The growth since the years prior to becoming a university of technology in 2000 is particularly large. In spite of the price of monographs rising by approximately 13\% per annum (Blanchard 1994:21), AUT has continued to increase materials budgets proportionately to enable the library to continue adding around 11,000 volumes per annum. In 1998, for example, the library's acquisition rate for monographs increased by $66 \%$ (Saw 1998:6). In that year, the capital budget for purchasing books increased by $10 \%$ and the number of library books in stock increased by $11,27 \%$ (Saw 1998:3). In 1999, the number of library books increased by 16\% (Saw 1999:2).

Support from the parent institution is the main reason the collection has been able to grow so quickly. The fact that the Deputy Vice Chancellor (Administration) and General Manager believes that a collection of 200,000 volumes is desirable ensures that institutional funds will continue to be channelled into the library to this end. It also indicates that the University has the funds available to channel to the library for this purpose, as the New Zealand Government had allocated sufficient funds to AUT to enable the technical college to upgrade to a university.

By 2003, the annual increase in the number of books acquired at AUT was similar to that of other universities of comparable size. The University Librarian stated in her annual report that:

Although the total collection size is still relatively small by university library standards, AUT is keeping up to

date with recent publications required for learning and research (Dewe 2003:3).

It is desirable that the budgets for monographs continue to support the level of growth shown in the past five years or even increase to enable AUT to reach the 200,000 volume target. This should be the minimum target for a university of technology of this size, taking into account the international standards for medium-sized academic libraries. It should also be borne in mind that approximately 50,000 English language scholarly and academic monographs are published each year (O'Connor \& Pugh 2000:65). As the 200,000 volume target was set in 200I, it is desirable that this minimum target be reached as quickly as possible, to obviate the situation where the library's book collection becomes increasingly outdated.

In Figure 3, the growth in the number of books in stock at AUT and XUT is compared. The growth in book stock is considerable at AUT, but is scarcely perceptible at XUT. From 1996 to 2000 (the years leading up to and including becoming a university of technology), AIT's book stock increased by 53\%. In the X Technikon library, from 2000 to 2004 (also the years leading up to and including their becoming a university of technology), the book collection increased by only 14\% from 45,872 to 52, I 70 volumes. Also, the increase at AUT was on a larger basic stock of books.

The lack of development in this part of XUT's collections should be seen in a serious light because of the esteem in which monographs are still held by many academics and researchers. These items are not usually included in aggregated services and researchers require access to these sources of information. According to Liu's (200I) study, an inadequate print collection is linked with an inferior academic institution and will over the course of time discourage quality scholars and researchers from remaining at or joining the staff of the institution. Unless the institution embarks on a campaign to bring the monographic collection in line with accepted standards and norms for medium-sized universities, the collection will become increasingly inadequate to meet the information needs of researchers and academics. This would detract from the credibility of XUT as a university of technology.

\subsubsection{Serials}

Serials are generally accepted as being the most valuable information resources to researchers and academics, especially to those in fields other than the humanities. As so many journals are now available in full-text aggregated services and taking into account the high prices of both print and electronic journals, collection developers must be very circumspect in decisions they make about subscriptions to print journals.

Figure 4 shows how the total number of subscriptions to print serial titles has grown since AIT began offering degree courses and is particularly marked after 2000 , when the institute became a university. What is important is that this period also saw a large increase in the number of titles accessed through online databases. Academics and researchers like to browse through print journals to find information or to discover new avenues for research, and the growth in print journal subscriptions shows a commitment on the part of AUT to meet the needs of their researchers and academics.

In 2002, the number of journal subscriptions peaked at 3,130 titles. In this year, additional funding was provided to purchase available back issues of currently held print serials (Dewe 2003:5). This provided continuous runs of some of the newer serial subscriptions. After 2002, titles were dropped again, presumably to avoid duplication of titles available electronically through aggregated services. This is understandable, especially in view of the costs involved in subscribing to these full-text databases and to the escalating price of journal subscriptions. Continuing to deselect print journal titles instead of extending this part of the collection would lead to an eventual erosion of the value of the serial collection at AUT. 


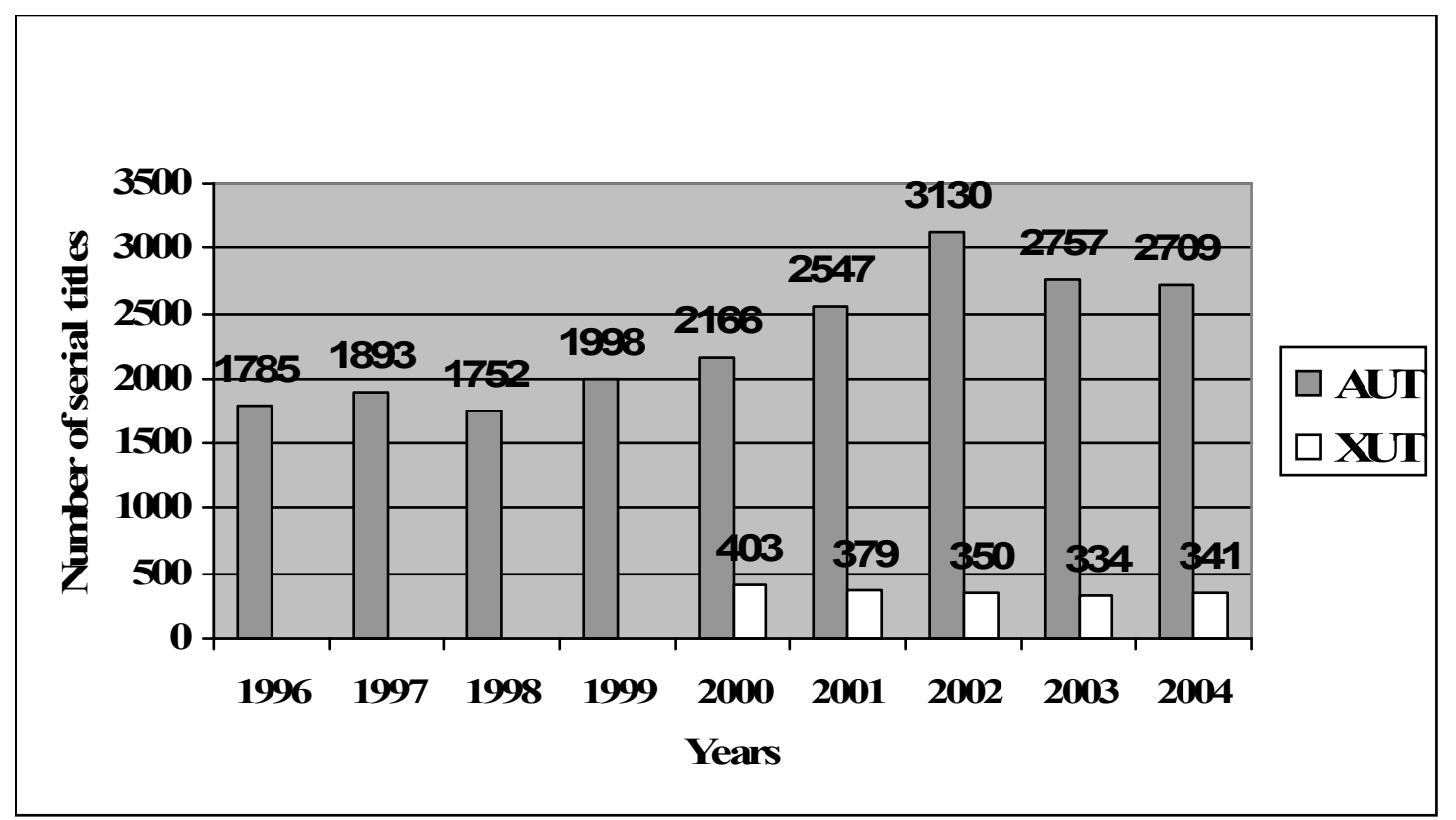

Figure 4 Print serial subscriptions

Of particular concern in the collection development practices at XUT is the steady decline in the number of print journal subscriptions in the five years leading up to their becoming a university of technology. In 2000 they subscribed to only 403 titles. Print journals are the preferred medium for the majority of scholars (Hiller 2002:8; Jirojwong and Wallin 200I:7I) and there are disadvantages to relying solely on electronic journals as sources of information.

One problem relating to depending on e-journal subscriptions is that this medium relies on expensive equipment. This is not affordable to institutions that lack adequate funding. The cost of hardware to access this medium is extremely high (Mgobozi \& Ocholla 2002:82; Nelson 200I:213). In addition to the cost of equipment, there are technical shortcomings of the hardware, software and networks required for the use of e-journals (Herman 200I:444). The cost of the e-journals themselves is high because in order to gain access to all the e-journals academics require, institutions would need to subscribe to a number of aggregated services as well as to many individual titles and the databases of multiple publishers (Mgobozi \& Ocholla 2002:82). There is an ongoing problem because the archiving of e-journals is inadequate, incomplete sets are offered and there is a lack of back issues (Rusch-Feja \& Siebeky 1999:1). In addition, libraries cannot rely on continuous access to these journals which makes them loath to cancel print subscriptions (Chroust 1998:377).

If XUT's serial collection were to be compared to those recommended in subject bibliographies, a more accurate reflection of the inadequacy of the collection at XUT could be shown.

Of further concern is that after 2000 , the number of titles subscribed to by XUT showed a steady decline. There is no evidence in their collection development policy that the decline in their collection of serials is going to cease in the future. In the years 2000 to 2004, there was a 15\% decrease in the number of titles to which XUT subscribes. In comparison, during the five years leading up to AUT becoming a university of technology, the number of serial subscriptions increased by $21 \%$. After this time, serial subscriptions increased by another $25 \%$, showing a desire to provide a collection of serials that will meet the information needs of researchers at a university.

Although many serial titles are now available in the form of e-journals in datasets, researchers have found that print copies are still the preferred medium (Hiller 2002:8; Jirojwong and Wallin 2001:71). Due to the need for researchers and scholars to browse through current journals, this researcher considers the serial collection at XUT to be substandard. There simply is not the range of journals needed by serious scholars and researchers to foster advanced study and research at XUT.

\subsubsection{Electronic resources}

AIT began in 198I to use overseas databases to find bibliographic information. This was done through introducing CDROM systems in the library (Blanchard 1994:7), which were considerably cheaper than using online databases (Blanchard 1994:20).

By 1996, there were twenty-three CD-ROM databases which formed a very significant part of the information retrieval tools in the Institute (Blanchard 1996:I5). Because CD-ROM is only of value if the disks are readily available, this entailed significant expenditure on equipment and on the Institute's network (Blanchard 1996: 17). In this same year, the 
library gained access to the Internet, and access to a number of online databases was through this channel (Blanchard 1996:15).

As technology developed, so AIT acquired an increasing number and array of electronic information resources. In 1997 they subscribed to 23 CD-ROM databases. In addition, they had three subscriptions to online databases (Saw 1997:19). In 1998, the number of CD-ROM products available through the library increased to 34 as well as II online services (Saw 1998:24). This meant that there was now access to I,418 full-text serial titles in electronic format. As online services became more popular in 1999, so these services began to overtake the number of CD-ROM databases in the library. In that year, the number of CD-ROM subscriptions dropped to 28 , whilst the number of online databases rose to 4 I (Saw 1999:24). These subscriptions meant that there was now access to 2,679 full-text electronic serial titles. This was an increase of $89 \%$ in one year. These new additions to the library's collection meant that the full-text serial titles now covered most areas that were relevant to AIT programmes and courses. It is important to remember that in that same year there was an increase of I4\% in the number of print journal subscriptions (Saw 1999:28).

A large number of new online databases were added to the collection in 2000 - the year in which the Institute became a university of technology, which increased the number of e-journal titles in stock to 5238 - a $97 \%$ increase. The following year, subscriptions to full-text serial titles increased by 1962 to 7,200 titles (Saw 2001:10). By the end of 2002, the library provided access to 8,396 full-text journal titles (Dewe 2002:4). This increase in access to online databases was largely attributable to the fact that the library continued to emphasise the acquisition of research-based electronic resources (Dewe 2002:6).

In 2002 AUT acquired its first e-books (Dewe 2002:4). This collection was expanded in 2003 by 700 titles. In 2004 the number of e-books rose to 2,500 .

In 2003 there was again a large increase in the number of full-text e-journal titles available through the AUT Library when the number of titles increased to 17,322 (Dewe 2003:10), an increase of 106\%. Additional funding was given in this year to acquire retrospective information resources. The acquisitions of digitised back files of research materials was effected through acquiring JSTOR (Dewe 2003:7). This initiative to provide back files to electronic resources was admirable as the lack of back files of e-journals is often cited as a limiting factor in using these resources.

It is becoming policy in Australasia that libraries do not have duplicate print and electronic subscriptions for serial titles. This decision is based mainly on budgetary constraints and also on storage facilities. The lack of a large collection of print serials has allowed AUT Library to move forward quickly with the adoption of e-resources. In 2004, additional databases were acquired, and access was provided to 38,476 full-text e-journals (Jenks 2005:3).

The increase in the number of electronic information resources available in the two libraries is depicted in Figure 5. At AUT, there has been an increase of 35,797 e-journal titles since becoming a university of technology at the beginning of 2000 (Jenks 2005:3). These titles are provided through approximately 150 databases.

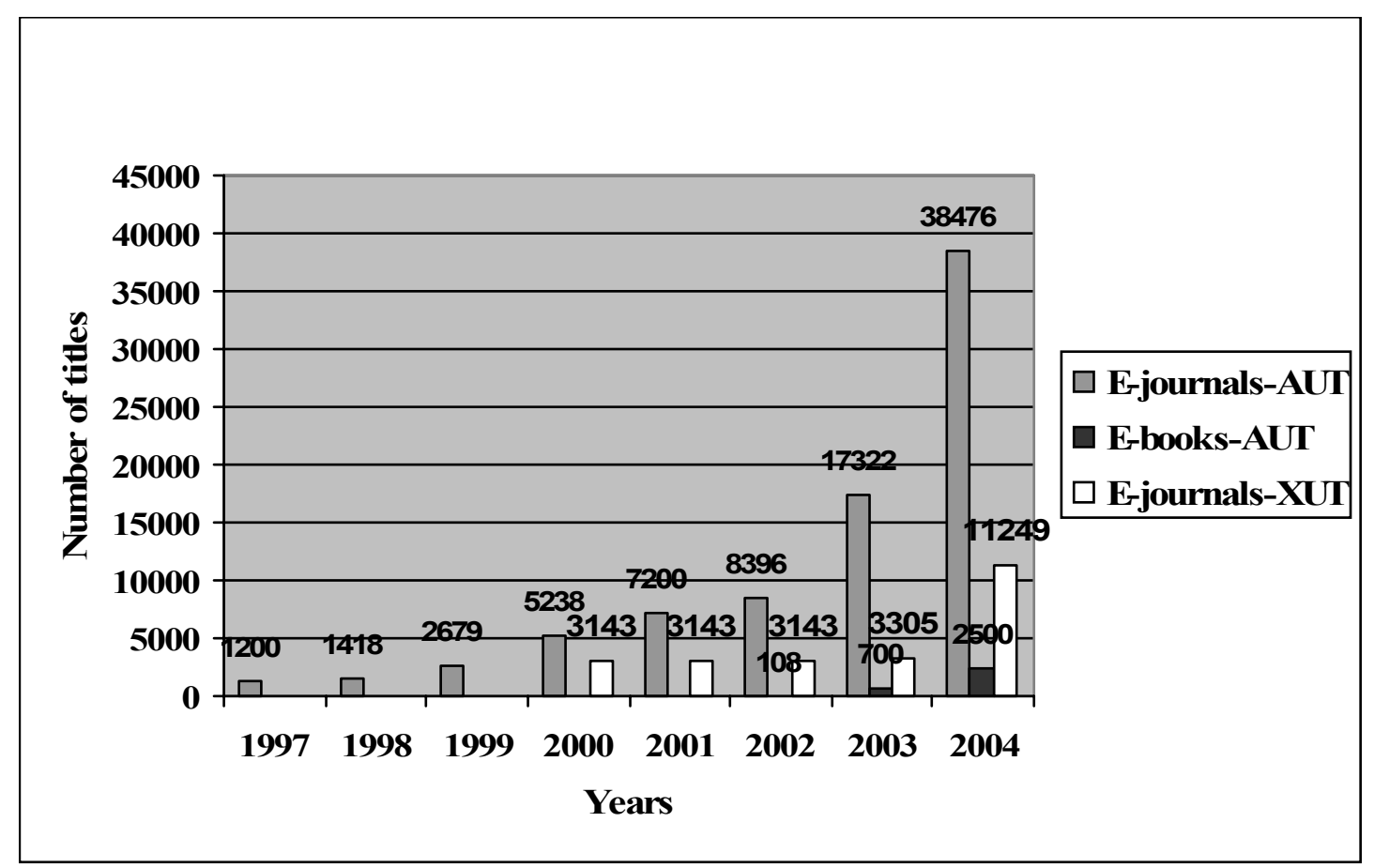

Figure 5 E-resources 
The development in the collection reflects the developments in information resources, and it would seem that the institution has done what was possible to reflect their changing status from polytechnic to university. Library management and the management of AUT itself have accepted the costly and complex challenge of becoming a university library. They realise that there are still shortcomings in the collection when AUT is compared to similar universities, but appear to be committed to bridging the gap from polytechnic to university. The resolve to continue building up the traditional collection as well as electronic resources can be seen clearly in the growth in all the most prevalent information formats available to them.

Historically, AUT and XUT followed the same patterns of acquisitions of electronic resources. Initially in the second half of the 1990s, XUT subscribed to a number of CD-ROM databases, mainly bibliographic databases containing metadata. Access to electronic resources was provided on a few networked computers in the library. They could also be accessed by technikon staff in their own offices.

As online databases became more accessible and subsequent to some deals negotiated by GAELIC, the consortium of academic libraries in Gauteng, XUT increased their serial collection substantially by subscribing to EBSCOHost and Emerald at the turn of the century. Through these databases, the library could provide access to full-text articles from approximately 3,120 journals. This added to the pool of e-journals to which users had access. Through IP recognition protocols, staff at the technikon could access any of these databases from their desktops, at other remote sites and in the library itself (Q 2005a:2).

In 2003, the bibliographic database INSPEC was added. In addition, SAejournals was added. Similarly to AUT, the beginning of the $21^{\text {st }}$ century saw the shift from CD-ROM databases to online internet-based databases.

As AUT approached the year in which it gained the status of a university of technology, the number of e-journals to which it had access increased each year. This increase was not seen at XUT. This can be seen in Figure 5 . In the year in which XUT became a university of technology, however, a dramatic increase is seen in the number of full-text e-journals available to academics, researchers and other library users. In 2004, this number rose to II,249 titles. This was made possible through subscribing to several new full-text databases. These included, Springer/Kluwer, ACS, ScienceDirect and the Compendex module of Engineering Village 2 (Q 2005b:2). This step is positive and goes some way to compensating for the poor state of the collection of traditional media in the library. As a result of these new subscriptions, the number of ejournals available has risen by $258 \%$ in the five years leading up to the institution becoming a university of technology. This growth is considerable and the new titles will benefit scholars in science and technology in particular. If this is the beginning of a trend to increase access to electronic resources, this part of the library's collection could grow into one that is more representative of a university of technology, instead of a technikon.

In addition to these full-text databases, in 2004 the XUT Library acquired I33 CD-ROMs (Q 2005b:2). These are for loan to library users and are not networked for users in the library or at remote sites ( $Q$ 2005a:2). There are also a number of bibliographic databases to which the library subscribes to help users find citations to relevant information. Another electronic resource available to library users is portals which provide links to useful online documents and websites. These were created by subject librarians to supplement the library's stock of information resources $(Q$ 2005a:2).

The XUT library has not yet subscribed to any e-books to supplement their small collection of monographs.

In spite of the increase in e-journals in 2004, the collection is still far below the international and national standards for research and university libraries. Unless the institution addresses this as a matter of urgency, it is doubtful whether the institution as a whole will be able to bridge the gap between a technikon and a university of technology. Should the library continue to lag behind in comparison to other South African university libraries, research and teaching programmes will fail to adhere to university standards and fail to attract recognised scholars as lecturers and researchers.

\section{Conclusion}

The case studies reveal that transforming a technikon library into a university library entails a great deal of planning, organisation and financial backing. It is not a process that occurs automatically. Without the necessary care, the libraries of former technikons might not be able to meet the information needs of researchers and academics at a university of technology.

AUT appears to have started planning for this since they were allowed to confer degrees in 1995. Budgets have risen and the higher levels of budgets have been increased steadily to the present. They have given care to building up collections in the various formats and are currently able to add items to their collections at the same rate as similar universities in New Zealand. It is possible that their print collections will never match the size of those of universities, but they are making every reasonable effort to supplement shortfalls with electronic books and journals. If their materials

SA Jnl Libs \& Info Sci 2006, 72(3) 
budgets continue to increase in line with those of other universities, over the years their collections will mirror the depth and breadth of similar universities, especially as far as recently published material is concerned.

XUT does not show the same planning and resolve to become a university library with collections similar to those of other medium-sized South African universities. The lack of understanding of the important role of print resources as information resources is a cause for concern. Meeting user needs with such a limited supply of print resources would only be possible if their collection of electronic resources were very much more extensive than it is at present. Without firm financial backing from XUT and ultimately from the National Department of Education, this shortfall cannot be addressed. This institution does not appear to have been able to make the necessary paradigm shift from technikon to university of technology.

It is commendable that attention is currently being given to increasing access to electronic media, but the progress is slow. Providing only the limited collection of resources currently on offer through the XUT library will limit the research output of that institution and, taking Liu's (2001:62) research into account, would probably discourage accredited scholars from joining the institution.

It is recommended that both institutions evaluate their collections against subject bibliographies and against the collections of peer institutions. They should then devise plans to overcome the shortfalls in the collections and ensure that there is adequate funding to meet these needs. It is extremely unlikely that a new university of technology will be able to develop their print collections to the same strength and depth as those of established universities, nor is this necessarily required. When the collections of established universities were being developed there were no e-resources available that could supplement print resources. The contribution of electronic media to a library's total collection of information resources could not have been foreseen at the time older university libraries were developing their collections. It is however essential that a new university of technology should set a reasonable target and the goal, once that target is met, should be to add to their collections at the same rate as do established universities in their countries in order to be comparable to other university libraries.

\section{References}

Blanchard, F. 1994. Auckland Institute of Technology Library - annual report. Auckland: Auckland Institute of Technology.

Blanchard, F. 1996. Auckland Institute of Technology Library - annual report. Auckland: Auckland Institute of Technology.

Chroust, D.Z. 1998. ALCTS Scholarly Communication Discussion Group. Library acquisitions: practice \& theory, 22(3):375-379.

Cochrane, T. \& Rickards, J. 199I. Support for research in a new university: a practical application of conspectus at the Queensland University of Technology. Australian library review, 8(2): 147-15I.

Dewe, A. 2002. Auckland University of Technology - Library annual report. Auckland: Auckland University of Technology.

Dewe, A. 2003. Auckland University of Technology - Library annual report. Auckland: Auckland University of Technology.

Jenks, H. 2005. Electronic mail. 12 May, Auckland, NZ.

Faculty use of an academic library reference collection. 1998. By M.J. Aked ... [et al.]. Collection building, 17(2):56-64.

Herman, E. 200I. End-users in academia: meeting the information needs of university researchers in an electronic age. Part 2, Innovative information-accessing opportunities and the researcher: user acceptance of IT-based information resources in academia. Aslib proceedings, 53(I0):431-458.

Hiller, S. 2002. How different are they? A comparison by academic area of library use, priorities, and information needs at the University of Washington. Issues in science and technology librarianship, 33:I-I3 [Online]: http:www.istl.org/ist//02-winter/ article I.html. Accessed 18 ${ }^{\text {th }}$ October 2002.

Jenks, H. 2005. Electronic mail. 12 May, Auckland, NZ.

Jirojwong, S. \& Wallin, M. 200I. Use of formal and informal methods to gain information among faculty at an Australian Regional University. Journal of academic librarianship, 27(I):68-73.

Kratwohl, D.R. 1993. Methods of educational and social science research: an integrated approach. New York: Longman.

Liu, L.G. 200I. The contribution of library collections to prestige of academic programs of universities: a quantitative analysis. Library collections, acquisitions, \& technical services, 25(I):49-65.

Mgobozi, M.N. \& Ocholla, D.N. 2002. The use of electronic journals for the dissemination of scholarly information by the University of Natal and the University of Zululand. South African journal of libraries and information science, 68(2):8I-93.

Nelson, D. 200I. The uptake of electronic journals by academics in the UK, their attitudes towards them and their potential impact on scholarly communication. Information services and use, 21:205-214.

O'Connor, S. \& Pugh, S. 2000. Collaborative purchasing: a model for financially straitened times. Collection management, 24(I/ 2):57-77.

Powell, N. \& Bushing, M. 199I. Collection evaluation workshops project: consultants report. New Zealand libraries, 46(II):912.

Q. 2005a. Electronic mail. 3 March, [S.I.].

Q. 2005b. Electronic mail. 23 May, [S.I.].

Rusch-Feja, D. \& Siebeky, U. 1999. Evaluation of usage and acceptance of electronic journals. D-lib magazine, 5(I0): I-4. [Online]: $h$ ttp://www.dlib.org/october99/rusch-feja/IOrusch-feja-sumary.html. Accessed $15^{\text {th }}$ June 2002.

Saw, G. 1997. Auckland Institute of Technology - Library annual report. Auckland: Auckland Institute of Technology.

Saw, G. 1998. Auckland Institute of Technology - Library annual report. Auckland: Auckland Institute of Technology.

Saw, G. 1999. Auckland University of Technology - Library annual report. Auckland: Auckland University of Technology.

SA Jnl Libs \& Info Sci 2006, 72(3) 
Saw, G. 200I. Auckland University of Technology - Library annual report. Auckland: Auckland University of Technology.

South Africa. Ministry of Education. 2003. Schedule: funding of public higher education. Pretoria: Government Printer.

South Africa. Ministry of Education. 2005. Ministerial statement on higher education funding: 2005/6 to 2007/8. Pretoria: Government Printer.

Soy, S.K. 1997. The case study as a research method. [Online]: http://www.gslis.utexas.edu/ ssoy/usesusers//39/dIb.htm. Accessed $15^{\text {th }}$ February 2006.

Van Zijl, C. 1999. [X] Technikon Library - Draft collection development policy. [S.I.]: [X] Technikon.

Van Zijl, C. 2002. Evaluation of Library Facilities and Services by [X] Technikon Staff. [S.I.]: [X] Technikon.

$X$ University of Technology. 200I. Strategic plan covering the period January 200I to December 2003 for the [X] Technikon. [S.I.]: $[\mathrm{X}]$ Technikon.

XUT see X University of Technology. 